\section{Hematuria in puerperium: an obstetrician's nightmare}

Meenakshi B. Chauhan, ${ }^{1}$

Vijeyata Sangwan, ${ }^{2}$ Vani Malhotra,

Smiti Nanda, ${ }^{1}$ Vandana Bhuria ${ }^{1}$

'Department of Obstetrics \& Gynecology, PG Institute of Medical Sciences, Rohtak; 2Department of Obstetrics \& Gynecology, BPS Medical College Khanpur, Sonepat, India

\section{Abstract}

Hematuria in the peripartum period can be a diagnostic dilemma. A series of three rare cases of peripartum hematuria have been reported. All the cases recovered with conservative treatment. Peripartum hematuria can be idiopathic. Intravenous pyelography is the investigation of choice to find out the cause. Conservative approach remains the main stay of treatment.

\section{Introduction}

Hematuria is the presence of blood in the urine, more than three red blood cells per high power microscopic field. The various causes of hematuria are infections like severe urinary tract infection and sexually transmitted diseases, calculi, trauma like a direct blow to the kidneys, tumors, renal parenchymal disease specially immunoglobulin A nephropathy, coagulation disorders, drugs, renal vein thrombosis and endometriosis. We are presenting these rare cases of peripartum hematuria where cause could not be diagnosed. In all cases hematuria resolved spontaneously during the postpartum period.

\section{Case Reports}

\section{Case \#1}

A 22-year-old primipara was referred to our tertiary care centre on her 13-postnatal-day on account of unexplained hematuria for seven days. Patient had a full term vaginal delivery 13 days back at a peripheral hospital. There was no history of prolonged labor or any trauma during delivery. She voided urine and passed stools comfortably after delivery. She developed difficulty in micturition, pain and distension of abdomen from her third postnatal day when she approached a private practitioner, where sonography was done and it suggested presence of left ovarian cyst of size 8 into 10 $\mathrm{cm}$. Exploratory laparotomy was performed which revealed bilateral normal ovaries and normal uterus. However the bladder was distended. A slow decompression of bladder was done and cystoscopy performed which revealed an edematous bladder. Patient was referred to our institute on account of continuing hematuria with catheter in situ draining hemorrhagic urine. There was no history of fever with chills and rigors at any time after delivery. Her complete hemogram, coagulation profile, liver and renal function tests were normal. Urine examination revealed $10-20$ pus cells and numerous red blood cells. Urine culture was sterile. Sonography of bladder revealed presence of blood clots in bladder. Urologist's opinion was sought who made a tentative diagnosis of cystitis and advised catheterization with triluminal catheter for bladder irrigation. Antibiotics and drugs to decrease bladder irritability were started. Catheter used to block repeatedly requiring frequent irrigation. On her $24^{\text {th }}$ postnatal day hematuria subsided and catheter was removed. Thereafter she needed intermittent catheterization for urinary retention, but slowly patient recovered completely as the urine became clear and she was able to pass urine without any difficulty with around $10 \mathrm{ml}$ of residual urine on sonography. Patient was discharged in satisfactory condition without any red blood cells in urine. At follow up after a fortnight she was passing urine normally and urine did not show any evidence of red blood cells (RBCs) or pus cells on microscopic examination.

\section{Case \#2}

A 30-year-old G4P1A2 was admitted in emergency with full term pregnancy with previous lower segment cesarean sections (LSCS) and symptoms of impending eclampsia. Her blood pressure (BP) at the time of admission was $160 / 110$ with proteinuria of $4+$ with hematuria. Her fetal heart rate was 80 per min. She was immediately taken up for emergency LSCS considering her to be impending eclampsia. Her bedside bleeding time was 7 min and clotting time was $8 \mathrm{~min} 30 \mathrm{~s}$. Peroperatively bladder was easily pushed down, previous scar was intact. A thick meconium stained male baby with Apgar score of 3 and 5 at 1 and 5 min respectively was delivered. Intraoperatively patient had hematuria, which also continued postoperatively. Investigations revealed severe anaemia with altered renal profile and coagulation profile. Her hemoglobin (Hb) was 5.0 gm, blood urea was $69 \mathrm{mg} / \mathrm{dL}$, serum creatinine was $4 \mathrm{mg} / \mathrm{dL}$, and serum uric acid was 6.5 $\mathrm{mg} / \mathrm{dL}$. Her prothrombin time was $30 \mathrm{~s}$; partial thromboplastin time was $60 \mathrm{~s}$ with an international normalized ratio of 2.2. Five units of packed cells and 7 units of fresh frozen plasma were transfused to her. Her BP became normal
Correspondence: Meenakshi B. Chauhan, 15/8FM, Medical Enclave, Rohtak (Haryana), India.

Tel.: +919416120892.

E-mail: mbc51490@yahoo.co.in

Key words: hematuria, peripartum, postnatal.

Received for publication: 18 December 2013. Revision received: 20 June 2014.

Accepted for publication: 19 September 2014.

This work is licensed under a Creative Commons Attribution NonCommercial 3.0 License (CC BYNC 3.0).

(C) Copyright M.B. Chauhan et al., 2014

Licensee PAGEPress, Italy

Urogynaecologia 2014; 28:157

doi:10.4081/uij.2014.157

after caesarean section and the urinary output remained adequate. Opinion of a renal physician was taken who advised a conservative approach since her output was normal. Her renal functions and $\mathrm{Hb}$ improved and coagulation profile became normal after two days but hematuria continued in the post-operative period. Sonography revealed clots in bladder. Cystoscopy did not show any evidence of trauma to bladder. Bladder was irrigated and catheter was removed on her $15^{\text {th }}$ postoperative day. Patient was discharged on her $20^{\text {th }}$ postoperative day when her hematuria resolved and urine examination was absolutely normal. On follow up at 6 weeks, a microscopic examination of urine was performed and it did not reveal any RBCs.

\section{Case \#3}

A 35-year-old G2P1 was admitted in emergency with full term pregnancy with previous history of LSCS 15 years back and a history of taking treatment for secondary infertility. She was normotensive and no other co morbid condition was found to be associated. A LSCS was performed for precious pregnancy. Preoperatively the urine was clear. Intraoperatively there was no problem in pushing the bladder down, scar was intact and there was no trauma to bladder. In the immediate postoperative period she developed hematuria. Coagulation profile was found to be normal and sonography showed clots in bladder. A self-retaining triluminal catheter was indwelled. Urine continued to be hemorrhagic. Urologist's opinion was taken who performed a cystoscopy, which did not show any evidence of trauma to bladder. Bladder irrigation was performed. Urine gradually became clear and the catheter was removed on $15^{\text {th }}$ postoperative day when urine did not show any microscopic hematuria. 
Analysis of her previous records revealed presence of hematuria after previous caesarean without any cause, which had resolved spontaneously after 10 days. She was discharged in satisfactory condition with advice to follow up after 15 days but she was lost to follow up.

\section{Discussion}

Pregnancy affects all the systems of body and urinary tract is not an exception. During pregnancy several changes occur in the renal system. High levels of progesterone and gonadotrophins act as smooth muscle relaxants. This causes increased elasticity of all urinary passages and decreased smooth muscle tone. ${ }^{1}$ The collecting system especially ureters had decreased peristaltic movements during pregnancy and most women in their third trimester show significant ureteral dilatation. ${ }^{2-4}$ The bladder also develops increased capacity and relative insensitivity to intravesical pressure. These above mentioned factors might be responsible for stasis of urine postnatally. ${ }^{5}$

Gravid uterus also had some mechanical effect on ureters. There occurs dilatation of ureters at the level of pelvic brim where they are compressed by the enlarging uterus. Furthermore the right ureter is almost always dilated more than the left one because of dextro-rotated uterus, prominence of right iliac artery and the cushioning effect of sigmoid colon on left side. ${ }^{6,7}$ Thus it is reasonable to assume that hormonal and mechanical factors are involved in the hydronephrotic changes during pregnancy. Pregnancy also increases vascularity of urinary system. Renal length increases approximately $1 \mathrm{~cm}$ during pregnancy due to increased renal vascularity and interstitial volume. ${ }^{8}$ Varicosities develops in the renal vein in the region of renal pelvis and upper ureter. Histologically ureter shows hyperplasia, hypertrophy and infiltration by lymphocytes, plasma cells and leukocytes. ${ }^{9}$ Renal function continues for varying periods in the face of marked to complete ureteral obstruction. In pregnancy, urine can egress through the partially obstructed ureters. Hinman and associates had shown that urine can escape from the obstructed renal pelvis through small tears in the pelvic mucosa in the region of fornices. ${ }^{10}$ After forniceal rupture urine may penetrate up to few millimeters in surrounding connective tissue. In some instances this extravasating urine may rupture the small arcuate or interlobular veins to establish channels between the renal pelvis and peripelvic veins (pyelovenous backflow). Of the various forms of extravasation, pyelovenous is the rarest and most severe form, probably requiring a higher and more rapid increase in intrarenal pelvic pressure..$^{11,12}$
During active stage of labor, in the presence of an already hydronephrotic collecting system with increased vascularity renal pelvic pressure increases that opens the pyelovenous channels. Bleeding through these channels can occur only if renal pelvic pressure exceeds the intrarenal pressure. ${ }^{13,14}$ Usually after delivery involution of uterus and withdrawal of progesterone causes relief from ureteral obstruction and return of ureteral tone. ${ }^{15}$ With these changes renal pelvic pressure decreases and closure of pyelovenous channels occurs and healing of forniceal tear takes place. But sometimes if these pyelovenous channels fails to close or are reopened by a sudden increase in ureteral obstruction as in acute retention of urine massive hemorrhage may occur. This condition can only be diagnosed by intravenous pyelography (IVP). Besides this, sudden relief of hydronephrosis may also cause hematuria due to mucosal tears in the distended renal pelvis. Nutcracker theory can also be an attempted explanation for such type of hemorrhage. According to this theory left renal vein gets compressed between aorta and superior mesenteric artery resulting in resistance to renal outflow in left renal vein. This results in development of an extensive collateral venous drainage system involving gonadal, capsular, suprarenal, lumber, azygos and periureteral veins. Extensive renal varicosities formed by these collaterals causing hematuria following their rupture into renal calyces. ${ }^{16}$ Renal angiography and venography can diagnose this syndrome. On cystoscopy hemorrhagic urine can be visualized coming from the left ureteral opening.

Treatment is always conservative. ${ }^{17}$ Hematuria has been reported in a pregnant woman with antiphospholipid syndrome on anticoagulant therapy. ${ }^{18}$ In our first case, patient developed retention of urine followed by hematuria, the cause may be sudden relief of hydronephrosis that occurred during her antenatal period. The importance lies in the fact that a laparotomy was performed at periphery due to misdiagnosis of ovarian cyst. In the second case patient had hematuria preoperatively with altered coagulation profile but it was persistent in postnatal period even after correction of coagulation profile. In third case also patient had causeless and recurrent hematuria. All the three patients were investigated by invasive and non-invasive methods but no abnormality was detected. Cystoscopy can identify a left renal origin thus differentiating nutcracker phenomenon from pyelovenous backflow. However cystoscopy was normal in our cases. Literature suggests that IVP may be a diagnostic modality that can help find the etiology of disease..$^{17}$ In these cases IVP, magnetic resonance imaging or computed tomographic scan was not performed as with a large number of patients in a tertiary care cen- ter of a developing country like India patients get a long waiting date for special investigations and in all the three cases hematuria had subsided within 15 days without leaving any residual stigma.

\section{Conclusions}

Peripartum hematuria can be debilitating at times specially after operative delivery when the risk of trauma to bladder has to be excluded. There can be multiple causes of hematuria and it can also be idiopathic like in case 1 and case 3 . In such cases conservative approach remains the main stay of treatment.

\section{References}

1. Corce P, Siqnorelli P, Chiapparini J, Dede A. Hydronephrosis in pregnancy. Ultrasonographic study. Minerva Ginecol 1994;46:147-53.

2. Fainstat T. Ureteral dilatation in pregnancy: a review. Obst Gynec Surv 1963;18:8458.

3. Jenkins RH, Wagenan VG. Clinical interpretation of pyeloureteral dilatation of pregnancy based on experimental studies. J Urol 1949;61:217-9.

4. Wagenan VG, Jenkins RH. Pyeloureteral dilatation of pregnancy after the death of fetus. Am J Obstet Gynecol 1918;56:1146.

5. Glavind K, Bjork J. Incidence and treatment of urinary retention postpartum. Int Urogynecol J 2003;14:119-21.

6. Strickland NR. Hydronephrosis in pregnancy, report of a case. Obstet Gynecol 1964;24:928-9.

7. HarrowBR, Sloane JA, Salhanick L. Etiology of the hydronephosis of the pregnancy. Surg Gynecol Obstet 1964;119:1042-5.

8. Cunningham FG, Leveno KJ, Bloom SL, et al. Maternal physiology. In: Cunningham FG, Williams JW, eds. Williams obstetrics, $23^{\text {rd }}$ ed. New York: Mc Graw Hill; 2010. p 123.

9. Kittredge WE, Crawley JR. Surgical renal lesions associated with pregnancy. JAMA 1956;162:1353-5.

10. Hinman F. Peripelvic extravasation during intravenous urography, evidence for an additional route for backflow after ureteral obstruction. J Urol 1961;85:385-7.

11. Kiil $F$. The function of the ureter and the renal pelvis: pressure recordings of the normal and diseased urinary tract in man. Philadelphia: WB Saunders Company; 1957. p 15.

12. Kohler R. Investigations on backflow in retrograde pyelography: roentgenological and clinical study. Acta Radiol 1953;39:1-92. 
13. Beckmann CF, Abrams HL. Idiopathic renal vein varices: incidence and significance. Radiology 1982;143:649-52.

14. Beinart C, Sniderman KW, Saddekni S, et al. Left renal vein hypertension: a cause of occult hematuria. Radiology 1982;145:647-50.

15. Cunningham FG, Leveno KJ, Bloom SL, et al. The puerperium. In: Cunningham FG,
Williams JW, eds. Williams obstetrics, $23^{\text {rd }}$ ed. New York: Mc Graw Hill; 2010. p 648649.

16. Stewart BH, Reiman G. Left renal venous hypertension "nutcracker" syndrome: managed by direct renocaval reimplantation. Urology 1982;20:365-9.

17. Wendel RG, Crawford DE, Hehman KN.
The Nutcracker phenomenon: an unusual cause for renal variscositoies with haematuria. J Urol 1980;123:761-3.

18. Kawaguchi S, Izumi K, Nohara T, et al. Severe renal hemorrhage in a pregnant woman complicated with antiphospholipid syndrome: a case report. Adv Urol 2011;2011:791094. 